\title{
BMJ Open 'My independent streak may get in the way': how older adults respond to falls prevention education in hospital
}

Anne-Marie Hill,, ${ }^{1,2}$ Jacqueline Francis-Coad, ${ }^{2,3}$ Terry P Haines, ${ }^{4,5}$ Nicholas Waldron, ${ }^{6,7}$ Christopher Etherton-Beer, ${ }^{8}$ Leon Flicker, ${ }^{8}$ Katharine Ingram, ${ }^{9}$ Steven M McPhail ${ }^{10,11}$

To cite: Hill A-M, FrancisCoad J, Haines TP, et al. 'My independent streak may get in the way': how older adults respond to falls prevention education in hospital. BMJ Open 2016;6:e012363. doi:10.1136/bmjopen-2016012363

- Prepublication history for this paper is available online. To view these files please visit the journal online (http://dx.doi.org/10.1136/ bmjopen-2016-012363)

Received 21 April 2016 Revised 21 June 2016 Accepted 5 July 2016

CrossMark

For numbered affiliations see end of article.

Correspondence to Dr Anne-Marie Hill; annemarie.hill@curtin.edu.au

\section{ABSTRACT}

Objectives: The aim of the study was to determine how providing individualised falls prevention education facilitated behaviour change from the perspective of older hospital patients on rehabilitation wards and what barriers they identified to engaging in preventive strategies.

Design: A prospective qualitative survey.

Methods: Older patients $(n=757)$ who were eligible (mini-mental state examination score $>23 / 30$ ) received falls prevention education while admitted to eight rehabilitation hospital wards in Western Australia. Subsequently, 610 participants were surveyed using a semistructured questionnaire to gain their response to the in-hospital education and their identified barriers to engaging in falls prevention strategies. Deductive content analysis was used to map responses against conceptual frameworks of health behaviour change and risk taking.

Results: Participants who responded $(n=473)$ stated that the education raised their awareness, knowledge and confidence to actively engage in falls prevention strategies, such as asking for assistance prior to mobilising. Participants' thoughts and feelings about their recovery were the main barriers they identified to engaging in safe strategies, including feeling overconfident or desiring to be independent and thinking that staff would be delayed in providing assistance. The most common task identified as potentially leading to risk-taking behaviour was needing to use the toilet.

Conclusions: Individualised education assists older hospital rehabilitation patients with good levels of cognition to engage in suitable falls prevention strategies while on the ward. Staff should engage with patients to understand their perceptions about their recovery and support patients to take an active role in planning their rehabilitation.

\section{INTRODUCTION}

Falls in hospital settings are a substantial and costly problem with incident rates reported in Australia, Europe and the UK of between 3.2 and 17 falls per 1000 patient bed days. ${ }^{1-4}$

\section{Strengths and limitations of this study}

- Findings provide direct feedback from over 450 patients regarding barriers they identified to engaging in safe behaviour while admitted to hospital rehabilitation wards.

- The study provides understanding about how falls prevention education can be provided for older hospital rehabilitation patients who have adequate levels of cognition, using a theoretical framework of health behaviour change.

- Findings are from one state health setting and may not be generalisable to different health settings.

Up to $30 \%$ of these falls can result in physical injury, and $\sim 2 \%$ result in fractures. ${ }^{1} 3$ Older patients in geriatric or rehabilitation wards are at increased risk of falls compared to other patient populations. ${ }^{2}{ }^{4}$ Multifactorial strategies have been found to have some effect in reducing in-hospital falls, but there is uncertainty about the type and amount of intervention components that should be provided. $^{5}{ }^{6}$ Previous randomised controlled trials (RCT) testing individual hospital fall prevention interventions have found that low-low beds and bed alarms do not reduce falls. $^{7-9}$

In hospital settings, falls most often occur when patients attempt to mobilise, particularly when mobilising to the toilet. ${ }^{10-12}$ Additionally, large studies have demonstrated that over $80 \%$ of falls are unwitnessed, meaning patients tend to fall when no staff are in attendance. ${ }^{13} 14$ This suggests that older patients may be attempting to engage in mobility tasks without appropriate assistance or mobility aids, which place them at an unnecessary high risk of falling.

Older patients recovering from illness or injury in hospital benefit from engaging in rehabilitation with the goal of regaining their premorbid level of functional mobility. This typically requires them to achieve 
gradual but safe progression of functional mobility tasks without placing them at excessive risk of falling. Previous qualitative work has identified factors leading older adults to take risks that could contribute to them falling while in hospital. ${ }^{15}$ Factors found to influence older patients' propensity to engage in risk-taking behaviours while in hospital included their willingness to ask for help, desire to test their physical boundaries, communication failures between older patients and health professionals caring for them and delayed provision of help. Therefore, finding a way to provide falls prevention education to older patients undergoing rehabilitation which would reduce unnecessary risk taking was required.

The authors of the present study recently conducted an RCT that evaluated providing individualised falls prevention education to older hospital patients in rehabilitation wards, called the Safe Recovery programme: ${ }^{16}$ the programme was designed and delivered using principles of health behaviour change and a sound pedagogical structure. ${ }^{17-20}$ Educators also provided training to staff to support the programme. Feedback obtained after they delivered the programme was that the education facilitated mutual understanding between staff and patients, which assisted patients to engage in falls prevention behaviours on the ward. ${ }^{21}$ The intervention reduced falls on aged care hospital rehabilitation wards by $40 \%$ and injury resulting from falls by $35 \%{ }^{22}$ The reduction in falls and injurious falls rates was observed across the whole ward and did not only occur in the subgroup of patients with adequate cognition who directly received the education. This large multicentre trial which provided education to over 750 patients provided a valuable opportunity to engage directly with older patients to gain their perspectives about how health education can work to effect a change in older adults' health behaviour, namely engagement in falls prevention strategies while undergoing rehabilitation in hospital. This could assist to facilitate further translation of the intervention into clinical practice.

Other studies have examined falls epidemiology using hospital incident reports which contain staff's observations and reports about how individual falls occurred on their hospital wards. ${ }^{4} 1011$ Qualitative studies have also interviewed patients and staff regarding why they think falls could occur on hospital wards. ${ }^{152324}$ However, the patients in the present trial were a unique cohort as they had been provided with effective, pedagogically sound education about falls and falls prevention on hospital wards. Therefore, these older hospital patients were well positioned to provide feedback about how falls education in hospitals is received by older patients, and an informed perspective about barriers that they perceived could prevent them from engaging in effective falls prevention strategies.

The purpose of the study was

1. To determine what older hospital patients', who were on rehabilitation wards, responses were to being provided with individualised falls prevention education;
2. To identify perceived barriers that hindered older patients who were on rehabilitation wards from engaging in falls prevention strategies while in hospital.

\section{METHODS \\ Ethics}

This study was conducted as part of a cluster randomised trial that took place on eight hospital rehabilitation wards. The trial was approved by The University of Notre Dame Australia and The Sir Charles Gairdner Group Human Research Ethics Committees (numbers 2012_141 and 012069F), and a waiver of consent was obtained for obtaining individual patient's or staff's consent. All participant data collected from the posteducation survey was de-identified and grouped across all sites prior to analysis.

\section{Design}

A prospective qualitative survey informing the process evaluation of a cluster RCT was undertaken. The study took a descriptive and explanatory approach with qualitative data being collected from a cohort of patients who received the intervention within the larger RCT. These patients were admitted to hospital rehabilitation wards which delivered the education intervention. The protocol and trial results have been described elsewhere. ${ }^{16} 22$

\section{Participants and setting}

Participants $(\mathrm{n}=757)$ were older patients who were admitted to one of eight hospital rehabilitation wards that participated in a cluster RCT in Western Australia in $2013 .^{22}$ The wards were situated in hospitals that provide acute and rehabilitation care, and ranged from wards that provided short-stay geriatric evaluation and management to those that provided geriatric rehabilitation. There were 1623 admissions to intervention wards. Of those, $56 \%$ (914) patients were deemed eligible, based on a cognitive screen, to receive the education, and 757 $(46.6 \%)$ received the education. ${ }^{22}$ These patients received the education because they were screened as having levels of cognition where they could potentially benefit from receiving education, assessed using the minimental state examination $(>23 / 30)$ or the abbreviated mental test score $(>7 / 10) .{ }^{25}{ }^{26}$ A more detailed description of the cohort has been provided previously. ${ }^{22}$ Briefly, these participants (mean age $81.4 \pm 9.3$ years and median (IQR) LOS 12 days (7-21)) were admitted to the participating wards for ongoing rehabilitation. Admission diagnoses included orthopaedic conditions such as fractures, cardiac and respiratory conditions and general functional decline.

\section{Data collection and procedure}

Participants who were admitted to the intervention wards and screened as being eligible to receive the intervention were provided with the education called the Safe Recovery programme, as soon as was practical after 
admission in addition to their usual care. This education programme has been described extensively elsewhere. ${ }^{18} 19$ In summary, participants viewed a DVD and were provided with a workbook, both of which provided information about the epidemiology of falls and falls prevention in hospitals. Trained educators subsequently conducted follow-up education sessions for each participant to personalise the education.

The education programme provided participants with a three-step message: (1) know if you need help, (2) ask for help and (3) wait for help. The educator facilitated participants to develop a personalised action plan consisting of strategies that allowed them to engage safely in required mobility tasks on the ward and work cooperatively with staff, such as by ringing the bell if they required help. The intervention was delivered to all eligible older patients admitted to the intervention wards. The educators also provided the hospital ward staff with feedback about the programme, which alerted the staff to support older patients to engage in effective strategies that would maintain safe mobility. Patients admitted to control wards continued to receive their usual care.

The educators collected data for the present study as part of a broader face-to-face survey of participants after they completed the education programme. Usually, the survey was administered 2-3 days after the final session, but participants could still receive extra education sessions after the survey if the patient or educator thought it was required. As part of this survey, participants were asked to list the three key strategies that formed part of their action plan and to nominate the strategy that they thought would be most effective in reducing their risk of falls. They were then asked an open-ended question: 'is there anything that could stop you from (naming participant's nominated strategy)?', whereby the participant could identify any barriers that they thought would prevent them undertaking their planned falls prevention strategies. Subsequently, the second open-ended question asked participants 'is there anything you would like to share with the educator team regarding the program?'. Participants' responses to these two questions were recorded verbatim. At the close of the face-to-face survey, the responses were read back to the participant to clarify and confirm meaning.

\section{Analysis}

Content analysis was undertaken using a deductive approach. ${ }^{27}$ All verbatim responses from participants were de-identified, extracted from the surveys and organised using Microsoft Excel prior to entry into NVivo (V.10 for Windows QSR International, NVivo V.10 Qualitative data analysis software, 2012) for further management. Two researchers (A-MH and JF-C) independently read through the data several times prior to development of a categorisation matrix, using the constructs of the health belief model (HBM) which had been used to develop and evaluate the education programme. $^{17} 20$ The HBM conceptualises that raising awareness of the threat or susceptibility to a condition and providing knowledge about the recommended behaviours to reduce the threat allow an individual to weigh up the benefits and barriers to engaging in the health behaviour concerned. Consequently, given suitable cues to action and having the self-efficacy or confidence and motivation, the individual will engage in the desired health behaviour. Codes therefore corresponded with the HBM constructs of awareness, knowledge, confidence and motivation and modifying factors. This conceptual framework applied to falls prevention is presented in figure 1,28 and its applicability to the education programme is presented in table 1 . The coding process was based on examining the words and phrases that participants used and coding them according to the identified categories; therefore, a phrase such as 'helping to make me aware' would be coded as awareness. Where data provided patterns of categorical responses, frequency counts were also undertaken. Coded data from the categorisation matrix were then grouped under higher order headings to reduce the number of categories, through the collapse of like and unlike categories. The abstraction process involved applying content-specific words to each category. Subcategories with similarities were then described using a generic category. A third researcher (SMM) who was not involved in data collection or coding was invited to scrutinise the coding and arbitrate any differences.

The nature of the education was that it facilitated strategies whereby patients could reduce their risk of falls. Therefore, analysis of the barriers that patients identified was based on a conceptual framework that had been constructed from a previous study, which interviewed patients and staff to understand why older adults might take risks in hospital that could lead to falls. ${ }^{15}$ The framework conceptualises that basic elements of risk taking can be described within three broad constructs: the older patient, the environment and the task to be attempted. The nature of risk taking itself is described within two categories: voluntary, where the patients feel they have a choice as to whether they attempt to perform the task, and enforced, where the older patient feels there is no alternative but to attempt to perform the task. Voluntary risk taking is further conceptualised to be either informed, where an older patient decides to take a risk when aware of the risks involved, or mal-informed, where the patient takes a risk but is not fully aware of the risks involved. The final review of analyses was conducted by the three researchers who met and viewed the coded results against the conceptual frameworks. All three researchers discussed the subcategories, generic categories and the conceptual frameworks to reach consensus.

\section{RESULTS}

During the main trial, $757(91 \%)$ of the eligible participants received the education programme. Of these 


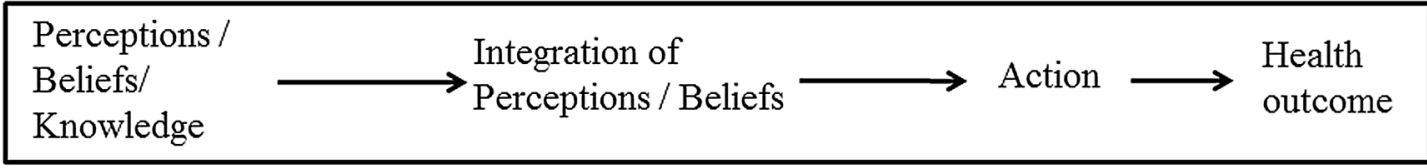

\section{Perception of risk of in-hospital falls \\ 2. Knowledge of falls risk - where and when in hospital that falls risk can be high \\ 3. Perception of severity of risk - that falls may lead to injury}

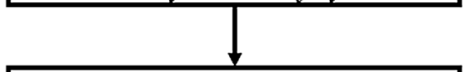

Anticipated benefits from trying to prevent falls to self outweigh anticipated costs of doing so

\begin{tabular}{|l|}
\hline 1. Knowledge of falls prevention \\
strategies \\
2. Belief that strategies intended to \\
prevent falls will reduce risk of \\
falls \\
3. Belief in own ability to attempt \\
falls prevention strategies
\end{tabular}

Figure 1 Constructs of the HBM framework applied to the patient education programme. Adapted from Hill et al. ${ }^{28} \mathrm{HBM}$, health belief model.

Table 1 Constructs of the HBM applied for providing individualised falls prevention education to older patients in hospital

\begin{tabular}{|c|c|c|}
\hline HBM construct & Definition & Application to falls prevention education \\
\hline $\begin{array}{l}\text { Perceived } \\
\text { susceptibility }\end{array}$ & $\begin{array}{l}\text { One's opinion of his/her chances of getting a } \\
\text { condition }\end{array}$ & $\begin{array}{l}\text { Personalise risk of falls based on person's mobility or } \\
\text { behaviour. } \\
\text { Raise perceived susceptibility, awareness of falls if too } \\
\text { low, provide information about when and where falls } \\
\text { occur in hospital }\end{array}$ \\
\hline $\begin{array}{l}\text { Perceived } \\
\text { severity }\end{array}$ & $\begin{array}{l}\text { One's opinion of how serious a condition and its } \\
\text { sequelae are }\end{array}$ & $\begin{array}{l}\text { Specify consequences of the risk of falls and injury that } \\
\text { results from falls }\end{array}$ \\
\hline $\begin{array}{l}\text { Perceived } \\
\text { benefits }\end{array}$ & $\begin{array}{l}\text { One's opinion of the efficacy of the advised } \\
\text { action to reduce risk or seriousness of impact }\end{array}$ & $\begin{array}{l}\text { Define action to take: how, where and when; to reduce } \\
\text { falls risk while a patient on hospital ward, clarify the } \\
\text { positive effects on mobility and safety to be expected }\end{array}$ \\
\hline $\begin{array}{l}\text { Perceived } \\
\text { barriers }\end{array}$ & $\begin{array}{l}\text { One's opinion of the tangible and psychological } \\
\text { costs of the advised action }\end{array}$ & $\begin{array}{l}\text { Identify and reduce barriers to engaging in falls risk } \\
\text { reduction strategies through reassurance, incentives, } \\
\text { support from staff and family }\end{array}$ \\
\hline Cues to action & Strategies to activate 'readiness' to change & $\begin{array}{l}\text { Provide how-to information about the strategies, } \\
\text { promote awareness, reminders of the cues to action } \\
\text { (such as keeping bell in reach, communicate with staff } \\
\text { about abilities and rehabilitation process) }\end{array}$ \\
\hline Self-efficacy & $\begin{array}{l}\text { Confidence in one's ability to take action, ie, } \\
\text { engage in falls prevention strategies, motivation } \\
\text { to take action }\end{array}$ & $\begin{array}{l}\text { Emphasise positive and achievable nature of required } \\
\text { actions. Training and support for performing falls } \\
\text { prevention behaviours, with graded feedback, staff, } \\
\text { educator, family provide positive feedback on actions } \\
\text { taken }\end{array}$ \\
\hline
\end{tabular}

participants, $704(92.3 \%)$ completed a written action plan, where participants were assisted to complete a written action plan that consisted of a number of goals. ${ }^{22}$ Goals took the form of practical strategies and were related to each participant's individual functional mobility in the context of their medical condition and 
were based on the behaviour modification and motivation messages contained in the Safe Recovery programme. Examples of frequently set goals by participants who were able to independently complete some or all of their mobility tasks were as follows: (1) use prescribed walking aid when walking and (2) get up slowly and check for dizziness before walking. Examples of frequently set goals by participants who required assistance of staff to mobilise were as follows: (1) keep the call-bell in reach at all times and (2) ask for help to get from the chair to the bed. Participants in total set 1643 goals for their action plan with a median of 2 (1-3) goals per participant. ${ }^{22}$

After the education was delivered, 610 (80.6\%) participants completed the post-education survey. The most frequent reason for not undertaking the survey was unanticipated discharge prior to the survey being administered. Of these participants, $473(77.5 \%)$ provided a response to the open-ended question regarding their perception of the education programme and 319 $(52.3 \%)$ provided a response about barriers they thought could prevent them from engaging in their planned safety behaviours on the ward. The most frequent reason for not providing a response about barriers $(n=158(25.9 \%))$ was that the participant needed to engage in other wards tasks and could not finish the survey.

The abstraction process identified subcategories that explained participants' responses to the education (presented in table 2). These subcategories were then mapped against the conceptual framework of the HBM (table 2).

Participants stated that the education "...makes you aware of what can happen... (p. 602)" and was "...excellent for increasing awareness; highlights need for safety (p. 198)," while another participant demonstrated raised awareness of thinking about falls prevention, stating “...I hope this will help keep me thinking before moving and only thinking about moving when I am moving (p. 109)."

Participants consistently reported that they gained knowledge from the education programme which was described as "...useful and interesting... (p. 189)" and "...very informative, told me what I needed to know (p. 6)." Participants also reflected that the education programme gave them the right amount of confidence, stating that it was "...helpful, makes you feel confident but not over-confident (p. 169)." Some participants specifically reported that they gained motivation and intended to engage in their planned falls prevention strategies such as "...this was very interesting and helpful and I will now speak up and ask more (p. 87)."

Participants also appeared to be motivated to engage with the programme because of the underlying programme design, with many stating that they "...thought the DVD was very good, well produced (p. 548)" and "...I learnt a lot from the DVD-very educational (p. 423)." They also commented on the appeal of the concrete, practical nature of the programme with one participant stating “...glad it's been raised, very practical, very wise move to present this information (p. 163)." A subgroup of older participants suggested that the education programme should be delivered to other older hospital patients as broadly as possible:

"Should be put out there more. Lots of people don't realise these things. It's quite correct, made me more aware, didn't realise things could happen (p. 394)."

A few participants felt that the education programme was of "...no benefit as just common sense... (p. 556)" with one participant stating that it was "common sense, a waste of time for me personally... (p. 331)." Some participants responded that choice to actively respond to the education was important, “...it's easier to make your own mind up when you what the results can be... (p. 12)." A few participants felt that maintaining one's own independence was paramount:

"I know, I know what you guys think I should be doing and I do understand but sometimes you just have to judge things yourself (p. 78)."

Participants' diverse range of responses indicated that the individualised nature of the programme helped them to develop tailored strategies which were relevant to them personally, demonstrating that the programme was able to be effectively delivered despite the heterogeneous clinical settings. For example, one participant responded that the education made them realise that “...(I) need to keep in mind that other people need help too, so be patient, not think you are the only one... (p. 435)" indicating gain in knowledge of ward procedure. Another participant gained knowledge specific to their own behaviour on the ward, stating "...it did make me understand why the nurses are always after me not to walk in my socks (p. 80)."

Participants' responses indicated that the nature of the education programme was effective in raising most participants' awareness about falls prevention, addressing gaps in their personal knowledge and allowing them to identify previously unrecognised risks of falling, while raising their motivation to engage in safe behaviour on the ward. When participants' responses to receiving the education programme were examined as a whole, these generic categories were able to be described by one main category of 'active engagement'. Most participants engaged with the education in a positive manner and responded actively to complete their falls prevention plan. Figure 2 summarises participants' responses within the conceptual framework of the HBM. This represented a conceptualisation of how the education programme could be effective in assisting participants to engage in the falls prevention strategies they had planned.

Barriers identified by participants to engaging in planned falls prevention strategies are presented in table 3. The most frequent barriers identified to engaging in safe falls prevention behaviours were their own thoughts and feelings about their recovery $(\mathrm{n}=205(64.3 \%))$, in 
Table 2 Participants' responses to the education programme

\begin{tabular}{|c|c|c|}
\hline $\begin{array}{l}\text { Frequency, } \\
\mathrm{N}=473(100 \%)\end{array}$ & HBM codes & Participants' survey responses \\
\hline $92(19.4)$ & Awareness & \\
\hline $40(8.5)$ & & $\begin{array}{l}\text { "...Made me more aware of falls risk... } \\
\text { (p. 239)," "...opened my eyes to the risk } \\
\text { of falls (o 550)" }\end{array}$ \\
\hline $31(6.5)$ & & $\begin{array}{l}\text { "...Puts it at the front of your mind... } \\
\text { (p. 186)," "...It is important to be safe } \\
\text { while getting well... (p. 14)" }\end{array}$ \\
\hline $21(4.4)$ & & $\begin{array}{l}\text { "...It makes me realise I need to think } \\
\text { about what I need to do until I am really } \\
\text { back to normal... (p. } 44), \text { " “...I ignored it } \\
\text { before like an idiot... (p. } 371 \text { )" }\end{array}$ \\
\hline $164(34.7)$ & Knowledge & \\
\hline $52(11)$ & & $\begin{array}{l}\text { "... This was good information to give to } \\
\text { all patients... (p. 131)," “...helpful } \\
\text { information... (p. 337)" }\end{array}$ \\
\hline $49(10.4)$ & & $\begin{array}{l}\text { "...Useful, covered all points... (p. 187)," } \\
\text { "...very helpful program... (p. 215)" }\end{array}$ \\
\hline $44(9.3)$ & & $\begin{array}{l}\text { “...Common sense, good to put theory } \\
\text { into practice... (p. 584)," “....all good } \\
\text { common sense... (p. 64)" }\end{array}$ \\
\hline $19(4)$ & & $\begin{array}{l}\text { "...Found it very interesting...," } \\
\text { "interesting: easy to follow... (p. 146)" }\end{array}$ \\
\hline
\end{tabular}

Subcategory

Increased awareness

of falls risk

Reflection about needing to be safe

Realised needs help/ will need to modify own behaviour

(p. 565)," “...watched DVD together with roommate enjoyed it very much... (p. 404)"

$36(7.6)$

35 (7.4) Confidence

"...Good, will make me think twice before attempting to go on my own... (p. 516)," "... will be careful and get help... (p. 306)" information is really obvious and I realise it applies to me as well... (p. 111)" "...Reminded me of previous learning... have been to falls clinic before... (p. 418)"
Informative

Useful/helpful

Common sense

Interesting

Good programmefeeling positive after programme

Enjoyment, excellent DVD

Motivated to change behaviour/empowering

Encouraging/reassuring

Confidence to engage in falls prevention strategies

Gives confidence

Modifying factors that facilitate taking action

Personal/social

circumstances

Knowledge about falls and falls prevention

Motivation to engage in falls prevention strategies

Prior learning 


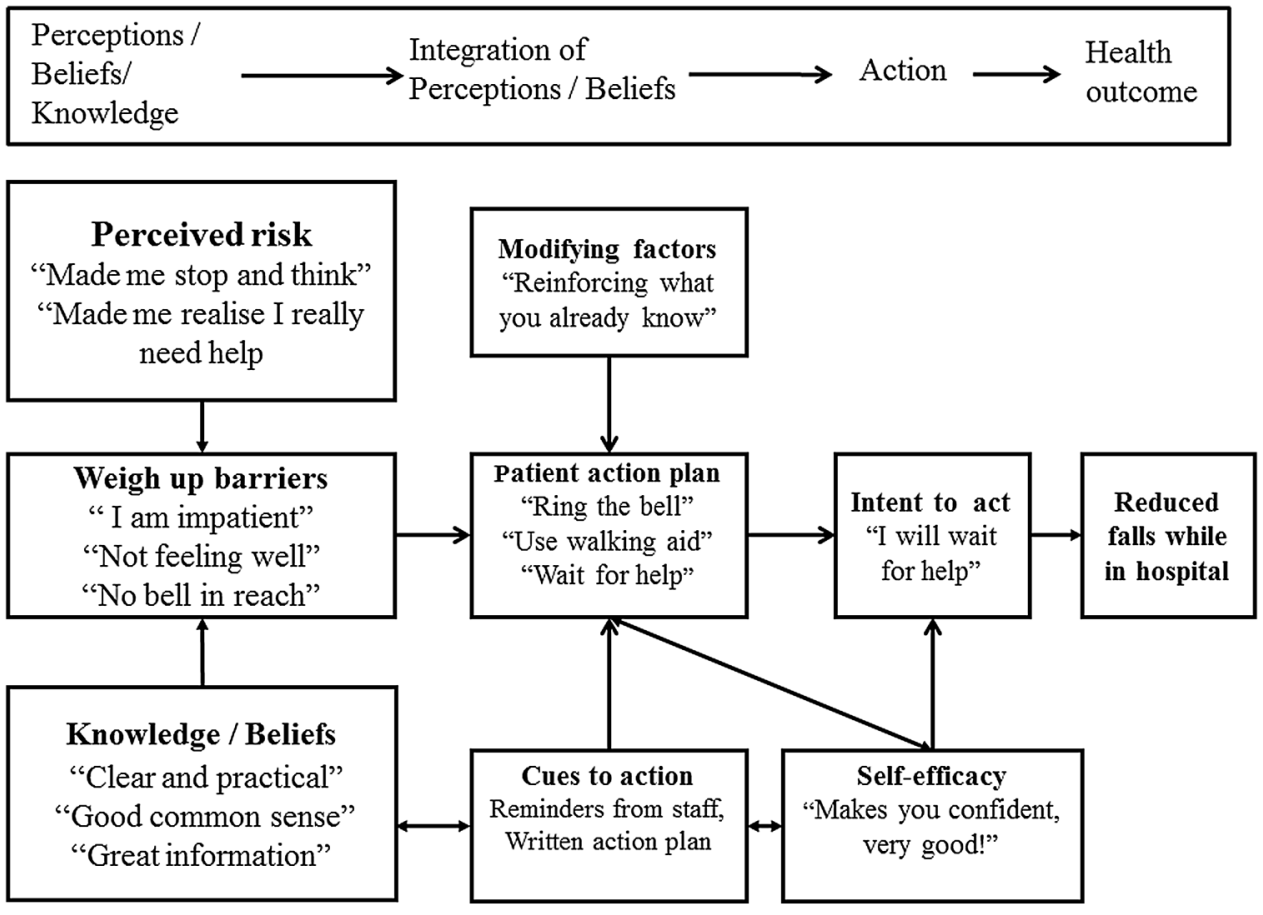

Figure 2 Participants' responses to receiving the falls prevention education mapped against the framework of the HBM. HBM, health belief model.

Table 3 Participants' identified barriers to engaging in their planned falls prevention strategies

\begin{tabular}{|c|c|c|c|}
\hline $\begin{array}{l}\text { Frequency, } \\
\mathrm{N}=319(100 \%)\end{array}$ & Participants' survey responses & Subcategory & $\begin{array}{l}\text { Generic } \\
\text { category }\end{array}$ \\
\hline $205(64.3)$ & & & Patient \\
\hline $27(8.5)$ & $\begin{array}{l}\text { "...I feel that I have been thinking I should be trying } \\
\text { everything now that I am so close to going home... } \\
\text { (p. 72)," "...the need to get myself stronger... (p. 6)" }\end{array}$ & $\begin{array}{l}\text { Thinking about recovery } \\
\text { process }\end{array}$ & \\
\hline $26(8.1)$ & $\begin{array}{l}\text { "...I don't have much patience you need to learn this } \\
\text { skill... (p. 114)" }\end{array}$ & Impatience/rushing & \\
\hline $13(4.1)$ & $\begin{array}{l}\text { "...My own independence-thinking I can do it myself... } \\
\text { (p. 367)," “...thinking I can do this little move safely... } \\
\text { (p. 127)" }\end{array}$ & Wanting to be independent & \\
\hline $15(4.7)$ & $\begin{array}{l}\text { "...Feeling overconfident that I can do it... (p. 101)," } \\
\text { "...over-estimating my abilities I feel very confident... } \\
\text { (p. 61)" }\end{array}$ & Overconfidence & \\
\hline $27(8.5)$ & $\begin{array}{l}\text { "Getting dizzy because I moved too fast... (p. 38)," } \\
\text { "...experiencing too much pain... (p. 261)" }\end{array}$ & Medical-related symptoms & \\
\hline $31(9.7)$ & $\begin{array}{l}\text { "...Thinking about something other than moving, not } \\
\text { focusing... (p. 123)," "....feeling unwell and not thinking... } \\
\text { (p. 391)" }\end{array}$ & $\begin{array}{l}\text { Difficulty thinking or } \\
\text { concentrating because } \\
\text { feeling unwell }\end{array}$ & \\
\hline $39(12.2)$ & $\begin{array}{l}\text { "...If staff take too long... (p. 51)," “...Nurses are always } \\
\text { very busy... (p. 586)" }\end{array}$ & $\begin{array}{l}\text { Thinking that there could be } \\
\text { delayed provision of help }\end{array}$ & \\
\hline $27(8.5)$ & $\begin{array}{l}\text { "...Not wanting to bother the nurses... (p. 244)," } \\
\text { "...thinking I am a fraud... (p. 96)" }\end{array}$ & $\begin{array}{l}\text { Feelings about seeking staff } \\
\text { assistance for tasks }\end{array}$ & \\
\hline $67(21.0)$ & & & Task \\
\hline 59 & $\begin{array}{l}\text { "...In case I need the toilet in a hurry... (p. 423)," "....only } \\
\text { if desperate to go to toilet... (p. 262)" }\end{array}$ & Going to the toilet & \\
\hline 8 & "...Being tired and wanting to get back into bed... (p. 47)" & Transferring to bed & \\
\hline $47(14.7)$ & & & Environment \\
\hline 30 & “...Bell out of reach... (p. 233)" & Call-bell use & \\
\hline 17 & $\begin{array}{l}\text { "...If frame not available... (p. 281)," “...seeing clutter } \\
\text { and not stopping and getting help... (p. 76)" }\end{array}$ & $\begin{array}{l}\text { Walking aid use/general } \\
\text { environment }\end{array}$ & \\
\hline
\end{tabular}


particular the desire to be independent and autonomous. This was evidenced by the frequency with which they responded that overoptimistic self-assessment could impact negatively on their decision-making. Participants stated that "...feeling overconfident that I can do it... (p. 101)" or "...my independent streak may get in the way (p. 92)" could be barriers to engaging in falls prevention strategies. Other participants identified this by stating that potential barriers were "...my own independence-thinking I can do it myself... (p. 367)" or "...overestimating my own strength (p. 117)." In addition, participants' perceptions about the recovery process extended towards staff and were also frequently identified as a barrier. There were $27(8.5 \%)$ participants who said that they "...felt like I am a burden and (have) lack of patience... (p. 112)" and other participants $(n=39(12.2 \%))$ suggested that they could find it difficult to engage in their planned strategies as “... nurses are always very busy (p. 586).” Participants also identified that "...not thinking and not concentrating... (p. 109)" made it difficult to remember to undertake safe strategies.

Toileting was the key task identified as a barrier to safely undertaking falls prevention strategies with 59 (18.5\%) participants identifying that it would be hard to keep to their plan of waiting for help or ringing the bell if they "...might want to go to toilet before they come (p. 389)." Figure 3 summarises participants' identified barriers to engaging in their chosen falls prevention strategy. Informed risk taking was the most frequent type of risk taken, while barriers that led to enforced risk taking were less frequently identified and were most likely to occur if participants urgently needed to use the toilet.

\section{DISCUSSION}

This large cohort of older hospital patients on rehabilitation wards who received the Safe Recovery education programme consistently reported that the education effectively increased their knowledge and awareness about falls and falls prevention and that they developed confidence and motivation to engage in individualised falls prevention strategies. These results are supported by a previous study, which found that providing patients on rehabilitation wards with falls prevention education using the multimedia component of this programme raised knowledge, confidence and motivation to engage in falls prevention strategies. ${ }^{18}$ However, the education programme in this trial also assisted participants to develop personalised strategies to reduce their falls risk on the ward and resulted in a significant reduction in falls. ${ }^{22}$ Participants' responses to receiving the education contrast with previous studies, which have found that older patients on either medical, rehabilitation, acute or subacute wards have low levels of awareness, knowledge and motivation to engage in falls prevention behaviours in hospital. ${ }^{15} 2324$

The findings of the present study are important as they explain how education resulted in a significant reduction in falls and injurious falls rates among older

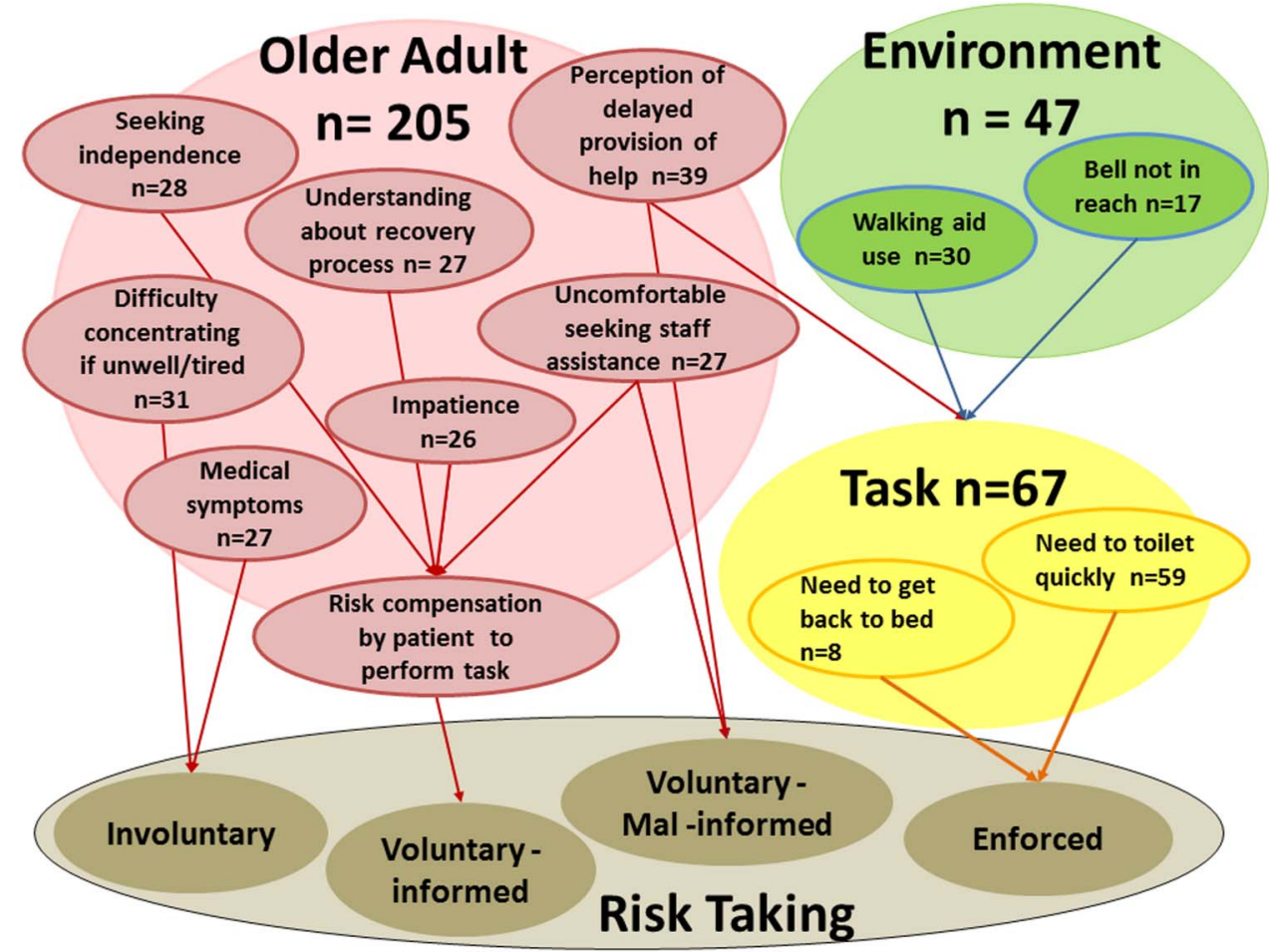

Figure 3 Participants' identified barriers to engaging in planned falls prevention strategies. Adapted framework from Haines et al. $^{15}$ 
patients when implemented in addition to usual care across eight hospital rehabilitation wards. ${ }^{22}$ The education programme was perceived by older participants as being 'enjoyable' and 'very interesting', in contrast to previous large community studies which have found that older people do not find falls information appealing or personally relevant and are not interested in finding out about how to reduce falls risk. ${ }^{29-31}$ Previous qualitative studies have also found that older patients can find falls prevention information confusing and can be passive about seeking out such education. ${ }^{23}{ }^{24}$ However, when asked, older people have stated that they would like clear information and explanation about the benefits of engaging in falls prevention strategies. ${ }^{32}$ Participants' positive responses to the programme were supported by earlier findings from educators of the programme. ${ }^{21}$ The educators suggested that the adult learning principles, which informed the education design, led to programme success. Allowing adults to be self-directive in their learning, acknowledging the experience the adult learner brings to the learning and ensuring content is personally relevant enhance engagement and motivation for learning. ${ }^{19}$ The educators felt that effectively engaging with the patient on this level was critical in facilitating development of patient motivation to participate in the programme. ${ }^{21}$ In the context of falls prevention education, this appeared helpful to overcome previous known barriers, namely that older people see little personal relevance and are reluctant to engage in discussion around falls and their prevention. ${ }^{23} 3031$

Participants' reported barriers to engaging in falls prevention strategies on rehabilitation wards were concordant with a previous conceptual framework that identified why older hospital patients might voluntarily engage in risk-taking behaviours that could lead to falls. ${ }^{15}$ Findings from the present study were from a much larger cohort and included a broad population of older hospital patients, providing further evidence in support of that framework. Participants' thoughts and feelings were found to be the most important element that contributed to risk-taking behaviour. These findings highlight the importance of ongoing discussion and negotiation with older patients, as part of providing individually tailored strategies. This approach facilitates older patients to undertake rehabilitation in a safe manner while on the ward. Other qualitative work has also found that ongoing communication about falls risk and strategies to patients and families is important in enhancing falls prevention on hospital wards. ${ }^{33}$ Concepts of health behaviour change explain that patients require social opportunity (both physical, such as having access to a walking frame, and psychological, such as positive reinforcement by staff) to engage in falls prevention activities. ${ }^{34}$ Participants' feedback was consistent with feedback from the educators who provided participants with the education programme. These educators reported that participants' beliefs and attitudes were key influences in either facilitating or forming a barrier to engagement in falls prevention strategies. ${ }^{21} \mathrm{~A}$ few participants responded less positively, feeling that they already knew what to do or could maintain their independence. It was not surprising that patients also reported that feeling anxious, ill or tired made it difficult to remember and concentrate on engaging in safe mobility. Older patients may need more consistent affirmation and support from staff to engage in safe strategies when undertaking mobility tasks in hospital, which has also been suggested by other researchers who have examined the provision of falls education for older patients on acute hospital wards. ${ }^{24}$ This may be particularly true of people who are usually independent and not used to receiving assistance. Previous studies have found that toileting is a mobility task that is strongly associated with falls occurrence in hospitals. ${ }^{10-12}$ However, the findings in this study confirmed other qualitative findings that suggest that even when undertaking the task of toileting, patients' perceptions about bothering staff or staff being too busy to help, rather than the task of toileting alone, contribute to toileting being identified as an activity that can heighten the risk of falls. ${ }^{24}$

This survey was limited by the nature of its administration. It was conducted among older hospital patients who were admitted to rehabilitation wards, and the focus was on providing patients with the programme and integrating the programme into patients' daily rehabilitation. Participants were invited to make a response if they desired to and the educator did not follow-up these responses with probing or discussion. Some participants did not choose to provide a response, which could have been due to fatigue, reluctance to answer survey questions or time limitation for openended questions if they needed to engage in other ward tasks. A strength of this study was that the feedback was obtained from a large cohort of patients with a broad range of diagnoses who were part of a cluster trial across eight hospital sites and hence were not a highly selective sample. Therefore, the sample and study findings are likely to be representative and generalisable to older rehabilitation patients who have appropriate levels of cognition to receive individualised patient education. This education was delivered as part of a cluster RCT, and in our original trial, the education was provided to $\sim 50 \%$ of the rehabilitation patients throughout the intervention wards, with the remaining patients screened as having impaired cognition. ${ }^{22}$ Staff were trained to support the programme. ${ }^{22}$ The study setting was also a usual ward environment, not a hypothetical scenario. Participants had first-hand experience of trying to engage in falls prevention strategies in a normal rehabilitation ward environment, meaning that their perceptions of barriers to engaging in fall prevention strategies were founded in their experiences of real-world ward operations and processes. A limitation of the study design was that the survey was administered by the falls prevention educators. This may have heightened moderator bias. Participants may have considered it to be 
socially undesirable to provide overtly negative responses about their education experiences directly to the educators. On the other hand, this may have also prompted participants to provide accurate responses regarding their goal setting and barriers to engagement as they were highly likely to have discussed personal goals and barriers during the education intervention sessions. We were also unable to interview staff at that time to gain their perception about the participants' understanding about ward falls prevention. This would assist to add trustworthiness to these findings. Another limitation of the study was that it was conducted solely among older patients who had received the Safe Recovery programme. Findings from this study may not be able to be generalised to other hospital education interventions, such as those provided for asthma or diabetes, as patients may need to engage in more complex strategies for these conditions and require ongoing staff instruction.

\section{CONCLUSION}

Older hospital patients admitted to rehabilitation wards with good levels of cognition, who were provided with individualised falls prevention education, reported that the education raised their awareness and knowledge about the risk of falls and falls prevention strategies. They also developed the confidence and motivation to engage in falls prevention by implementing individualised planned strategies. The main barrier they identified to engaging in such strategies was their own thoughts and feelings about their recovery, which could result in them engaging in risk-taking activity. Ongoing communication between patients and staff about the process of recovery is important in assisting older rehabilitation patients, who have adequate levels of cognition, to engage in falls prevention strategies while they are in hospital. Future research should continue to investigate how to provide effective falls prevention education in hospitals for other older patient populations.

\section{Author affiliations}

${ }^{1}$ School of Physiotherapy and Exercise Science, Curtin University, Perth, Western Australia, Australia

${ }^{2}$ Institute for Health Research, The University of Notre Dame Australia, Fremantle, Western Australia, Australia

${ }^{3}$ School of Physiotherapy, The University of Notre Dame Australia, Fremantle, Western Australia, Australia

${ }^{4}$ Department of Physiotherapy, Monash University, Melbourne, Victoria, Australia

${ }^{5}$ Allied Health Research Unit, Monash Health, Melbourne, Victoria, Australia ${ }^{6}$ Department of Rehabilitation and Aged Care, Armadale Kelmscott Memorial Hospital, Perth, Western Australia, Australia

${ }^{7}$ Health Strategy and Networks, Strategic System, Policy \& Planning, Department of Health, Government of Western Australia, Perth, Western Australia, Australia

${ }^{8}$ WA Centre for Health and Ageing, Royal Perth Hospital Unit, School of Medicine \& Pharmacology and Centre for Medical Research, University of Western Australia, Perth, Western Australia, Australia

${ }^{9}$ Department of Rehabilitation and Aged Care, Sir Charles Gairdner Hospital, Perth, Western Australia, Australia

${ }^{10}$ Centre for Functioning and Health Research, Metro South Health, Brisbane, Queensland, Australia
${ }^{11}$ Institute of Health and Biomedical Innovation and School of Public Health \& Social Work, Queensland University of Technology, Brisbane, Queensland, Australia

Acknowledgements SMM and TPH are supported by National Health and Medical Research Council (of Australia) Career Development awards.

Contributors A-MH contributed to study conception, design, intervention training, data collection and analyses, principal manuscript drafting and editing. SMM contributed to study conception, design, data management and analyses, manuscript drafting, appraisal and editing. JF-C contributed to study conception, design, data collection and analyses, manuscript drafting, appraisal and editing. NW, CE-B, LF and KI contributed to study conception, design, and site management and provided advice on data collection, management and analysis. TPH contributed to study conception and design and intervention training. All authors contributed to manuscript appraisal, revision and editing and read and approved the final manuscript.

Funding This work was supported by the Western Australian State Health Research Advisory Council and the Department of Health, Western Australia as part of the Research Translation Projects programme. This programme was established to encourage research and translation of outcomes into healthcare policy and practice. The key aim of the projects is to demonstrate improved cost-effectiveness and/or efficiencies to WA Health while maintaining or improving patient outcomes.

Competing interests None declared.

Ethics approval Ethical approval was obtained from The University of Notre Dame Australia HREC and Sir Charles Gairdner Hospital (North Metropolitan Health Service Department Health WA) HREC.

Provenance and peer review Not commissioned; externally peer reviewed.

Data sharing statement No additional data are available.

Open Access This is an Open Access article distributed in accordance with the Creative Commons Attribution Non Commercial (CC BY-NC 4.0) license, which permits others to distribute, remix, adapt, build upon this work noncommercially, and license their derivative works on different terms, provided the original work is properly cited and the use is non-commercial. See: http:// creativecommons.org/licenses/by-nc/4.0/

\section{REFERENCES}

1. Haines TP, Hill AM, Hill KD, et al. Patient education to prevent falls among older hospital inpatients: a randomized controlled trial. Arch Intern Med 2011;171:516-24.

2. Haines TP, Hill KD, Bennell KL, et al. Patient education to prevent falls in subacute care. Clin Rehabil 2006;20:970-9.

3. Healey F, Scobie S, Oliver D, et al. Falls in English and Welsh hospitals: a national observational study based on retrospective analysis of 12 months of patient safety incident reports. Qual Saf Health Care 2008;17:424-30.

4. Schwendimann R, Bühler H, De Geest $\mathrm{S}$, et al. Characteristics of hospital inpatient falls across clinical departments. Gerontology 2008:54:342-8.

5. Coussement J, De Paepe L, Schwendimann R, et al. Interventions for preventing falls in acute- and chronic-care hospitals: a systematic review and meta-analysis. J Am Geriatr Soc 2008;56:29-36.

6. Hempel S, Newberry S, Wang Z, et al. Hospital fall prevention: a systematic review of implementation, components, adherence, and effectiveness. J Am Geriatr Soc 2013;61:483-94.

7. Haines TP, Bell RA, Varghese PN. Pragmatic, cluster randomized trial of a policy to introduce low-low beds to hospital wards for the prevention of falls and fall injuries. J Am Geriatr Soc 2010;58:435-41.

8. Shorr RI, Chandler AM, Mion LC, et al. Effects of an intervention to increase bed alarm use to prevent falls in hospitalized patients: a cluster randomized trial. Ann Intern Med 2012;157:692-9.

9. Sahota O, Drummond A, Kendrick D, et al. REFINE (REducing Falls in In-patieNt Elderly) using bed and bedside chair pressure sensors linked to radio-pagers in acute hospital care: a randomised controlled trial. Age Ageing 2014;43:247-53.

10. Hitcho EB, Krauss MJ, Birge $S$, et al. Characteristics and circumstances of falls in a hospital setting. A prospective analysis. J Gen Intern Med 2004;19:732-9. 
11. Krauss MJ, Nguyen SL, Dunagan WC, et al. Circumstances of patient falls and injuries in 9 hospitals in a midwestern healthcare system. Infect Control Hosp Epidemiol 2007;28:544-50.

12. Oliver D, Healey F, Haines TP. Preventing falls and fall-related injuries in hospitals. Clin Geriatr Med 2010;26:645-92.

13. Hill AM, Hoffmann T, Hill K, et al. Measuring falls events in acute hospitals-a comparison of three reporting methods to identify missing data in the hospital reporting system. J Am Geriatr Soc 2010;58:1347-52.

14. Staggs VS, Mion LC, Shorr RI. Assisted and unassisted falls: different events, different outcomes, different implications for quality of hospital care. Jt Comm J Qual Patient Saf 2014;40:358-64.

15. Haines TP, Lee DC, O'Connell B, et al. Why do hospitalized older adults take risks that may lead to falls? Health Expect 2015;18:233-49.

16. Hill AM, Waldron N, Etherton-Beer C, et al. A stepped-wedge cluster randomised controlled trial for evaluating rates of falls among inpatients in aged care rehabilitation units receiving tailored multimedia education in addition to usual care: a trial protocol. BMJ Open 2014;4:e004195.

17. Abraham C, Sheeran P. The health belief model. In: Conner M, Norman $\mathrm{P}$, eds. Predicting health behaviour: research and practice with social cognition models. 2nd edn. Berkshire, UK: Open University Press, 2005:28-80.

18. Hill AM, McPhail S, Hoffmann T, et al. A randomized trial comparing digital video disc with written delivery of falls prevention education for older patients in hospital. J Am Geriatr Soc 2009;57:1458-63.

19. Merriam S, Bierema L. Adult learning: linking theory and practice. San Francisco, CA: Jossey-Bass (Wiley), 2014.

20. Janz NK, Becker MH. The health belief model: a decade later. Health Educ Q 1984;11:1-47.

21. Hill AM, McPhail SM, Francis-Coad J, et al. Educators' perspectives about how older hospital patients can engage in a falls prevention education programme: a qualitative process evaluation. BMJ Open 2015;5:e009780.

22. Hill AM, McPhail SM, Waldron N, et al. Fall rates in hospital rehabilitation units after individualised patient and staff education programmes: a pragmatic, stepped-wedge, cluster-randomised controlled trial. Lancet 2015;385:2592-9.

23. Lee DC, McDermott F, Hoffmann T, et al. 'They will tell me if there is a problem': limited discussion between health professionals, older adults and their caregivers on falls prevention during and after hospitalization. Health Educ Res 2013;28:1051-66.

24. Carroll DL, Dykes PC, Hurley AC. Patients' perspectives of falling while in an acute care hospital and suggestions for prevention. Appl Nurs Res 2010;23:238-41.

25. Folstein MF, Folstein SE, McHugh PR. "Mini-mental state". A practical method for grading the cognitive state of patients for the clinician. J Psychiatr Res 1975;12:189-98.

26. Hodkinson HM. Evaluation of a mental test score for assessment of mental impairment in the elderly. 1972. Age Ageing 2012; 41(Suppl 3):iii35-40.

27. Elo $\mathrm{S}$, Kyngäs $\mathrm{H}$. The qualitative content analysis process. J AdV Nurs 2008;62:107-15.

28. Hill AM, Hill K, Brauer S, et al. Evaluation of the effect of patient education on rates of falls in older hospital patients: description of a randomised controlled trial. BMC Geriatr 2009;9:14

29. Haines TP, Day L, Hill KD, et al. 'Better for others than for me': a belief that should shape our efforts to promote participation in falls prevention strategies. Arch Gerontol Geriatr 2014;59:136-44.

30. Dorresteijn TA, Rixt Zijlstra GA, Van Eijs YJ, et al. Older people's preferences regarding programme formats for managing concerns about falls. Age Ageing 2012;41:474-81.

31. Yardley L, Bishop FL, Beyer N, et al. Older people's views of falls-prevention interventions in six European countries. Gerontologist 2006;46:650-60.

32. Dickinson A, Machen I, Horton K, et al. Fall prevention in the community: what older people say they need. $\mathrm{Br} J$ Community Nurs 2011;16:174-80.

33. Dykes PC, Carroll DL, Hurley AC, et al. Why do patients in acute care hospitals fall? J Nurs Adm 2009;39:299-304.

34. Michie S, van Stralen MM, West R. The behaviour change wheel: a new method for characterising and designing behaviour change interventions. Implement Sci 2011;6:42. 